NASZA DERMATOLOGIA Online OUR DERMATOLOGY Online

Source of Support: Nil

Competing Interests: None

\section{GRANULAR PARAKERATOSIS: REPORT OF 2 ECUADORIAN CASES AND REVIEW OF THE LITERATURE}

\author{
Verónica Uraga ${ }^{1}$, Andrea Lubkov ${ }^{1}$, Annette Morán ${ }^{1}$, \\ Juan Carlos Garcés ${ }^{2}$, Enrique Uraga ${ }^{1,2}$ \\ ${ }^{1}$ Centro Privado de Piel "Dr Enrique Uraga Peña" Guayaquil, Ecuador \\ ${ }^{2}$ Hospital Luis Vernaza, Guayaquil, Ecuador
}

Corresponding author: Dr. Veronica Uraga

veronica_uraga@hotmail.com

\begin{abstract}
Granular Parakeratosis is a rare disorder of keratinization usually presented in adults. There are only fews reports in children. We present two cases, one in an adult and the other in a 7-month-old infant.
\end{abstract}

Key words: parakeratosis; keratosis; infant

\section{Introduction}

Granular parakeratosis (originally termed axillary granular parakeratosis) is a rare, recently recognized, acquired benign disorder of keratinization. It was first described in adults, and there are only a few reports of children with granular parakeratosis (GP), affecting predominantly the diaper area. We describe a case in a 37 years old man, and an additional case of a 7-month-old infant with GP.

\section{Case Report}

Case 1

A 32-year-old male patient presented for evaluation of a bilateral papillomatous axillary rash that had persisted for the past 3 months (Fig. 1). He reported that his lesions were slightly pruritic and that he has seen his primary care provider previously for his problem. He has been applying an antifungal cream per his recommendation that resulted in no improvement after 1 month of treatment. He denied the use of new deodorants or antitranspirants but he did mentioned that he sweats profusely and that he needs to reapply deodorant several times a day. Biopsy reported granular parakeratosis. Patient was treated with topical tretinoin.

\section{Case 2}

A healthy 7-month-old Ecuadorian boy of Asian descent presented with a 2-month history of an asymptomatic "warty eruption" distributed over his neck and antecubital fossae. The patient's mother denied the use of topical preparations or medications in these areas prior to the appearance of the rash.
His past medical history was unremarkable and there was no family history of cutaneous disorders. According to his mother, these lesions had recurred after having partially improved with the application of topical corticosteroids prescribed by his pediatrician.

Clinical examination revealed multiple, discrete, coalescing 2 to $3 \mathrm{~mm}$ brownish-eythematous hyperkeratotic papules located in his neck folds (Fig. 2, 3), and similar, but less pronounced lesions along the antecubital fossae (Fig. 4). The eruption was symmetric and no pain could be elicited on palpation. The rest of his skin examination was normal.

A biopsy specimen obtained from his neck showed marked hyperkeratosis and slight waviness of the epidermal surface. Discrete thinning of the stratum malphigii and preservation of the keratohyalin granules within a diffuse parakeratotic straum corneum. A mild superficial perivascular infiltrate of lymphocytes was also present (Fig. 5). These findings are characteristic of those described in granular hyperkeratosis.

After establishing the diagnosis, the patient was treated with $0,025 \%$ tretinoin cream with complete clearance of the lesions after 5 days. No known recurrence of the eruption has been documented so far.

\section{Discussion}

In 1991, Northcutt et al used the term Axillary granular parakeratosis to describe a peculiar axillary eruption with distinctive histopathological features in 4 middle-aged to elderly patients [1]. The rash consisted of unilateral or bilateral bright red patches with hyperpigmentation associated with pruritus. 


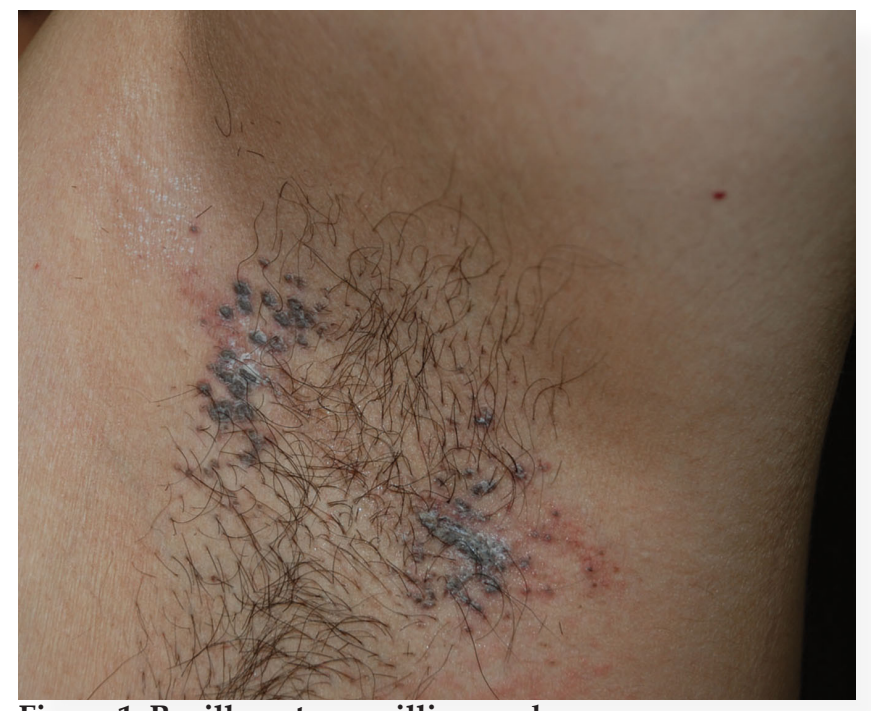

Figure 1. Papillomatous axilliary rash

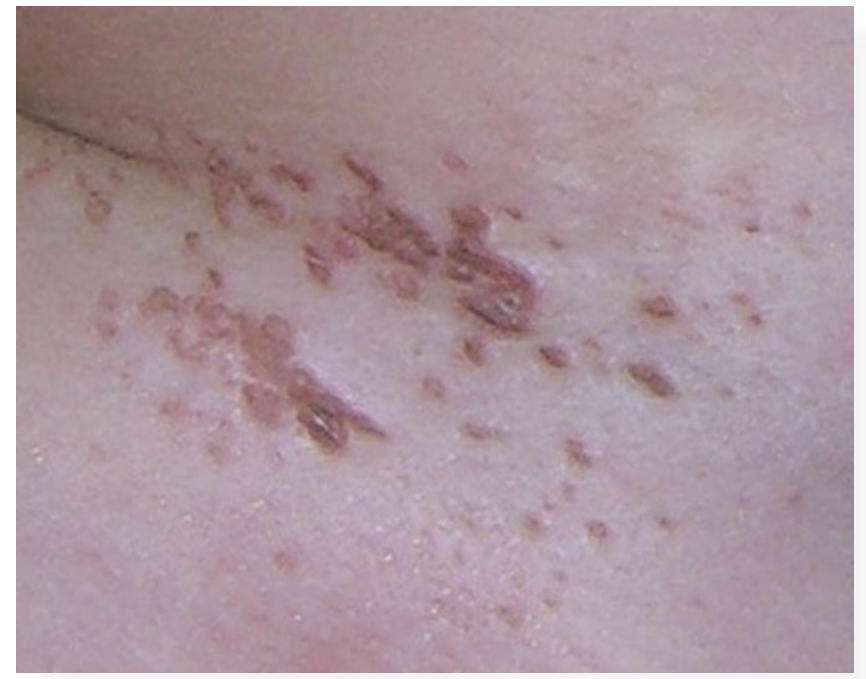

Figure 3. Close up of the neck fold lesions

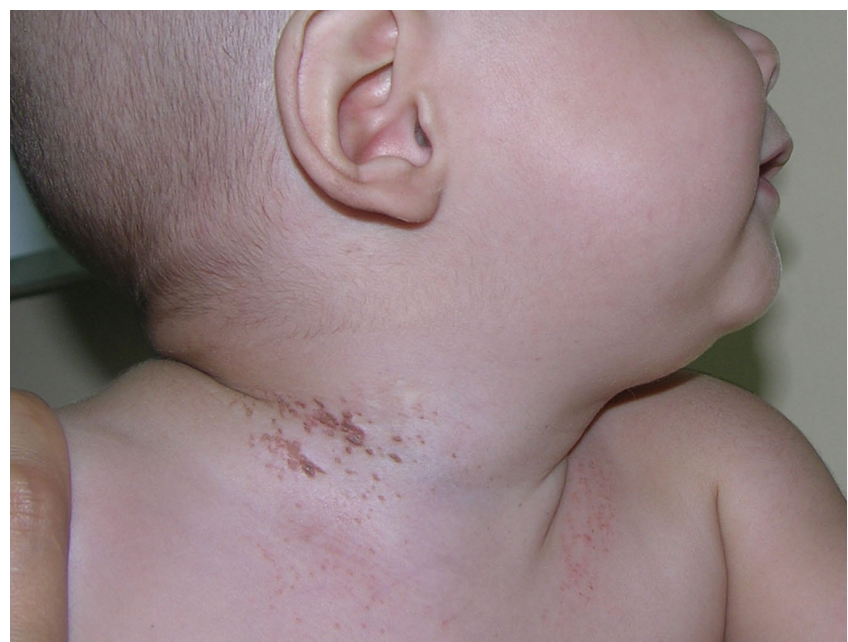

Figure 2. Multiple brownish-red scaly papules that focally coalesce located on the neck fold of the patient

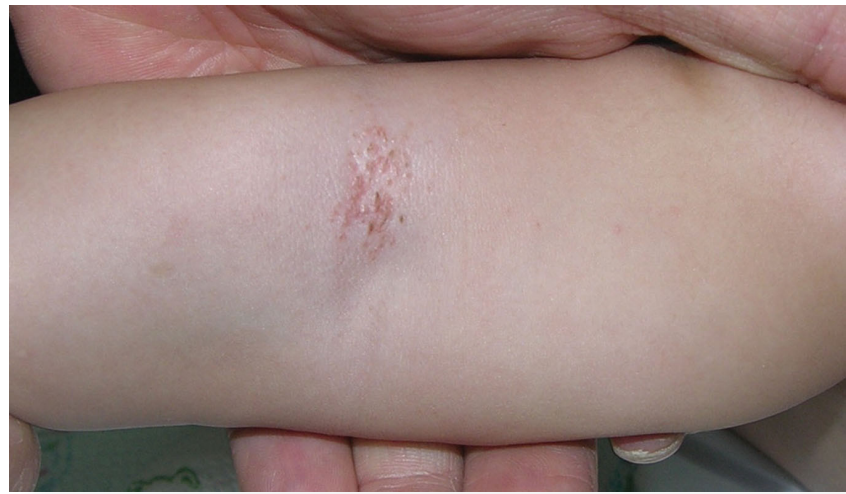

Figure 4. Clinical appearance of granular parakeratosis in the antecubital fossa of the patient

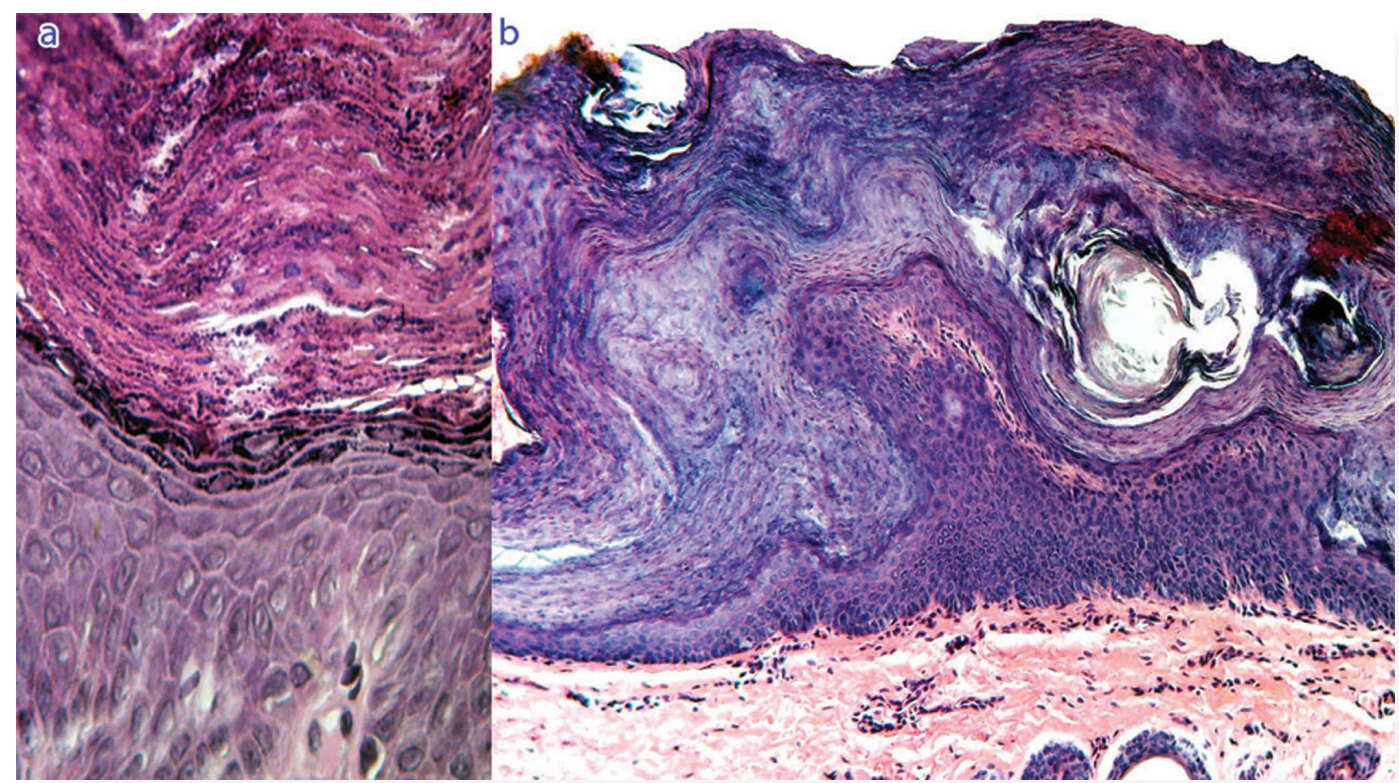

Figure 5a. Biopsy from the neck of the patient demonstrating hyperkeratosis with marked and diffuse parakeratosis.

Figure $5 \mathrm{~b}$. High power magnification showing retention of the keratohyaline granules in the stratum corneum 
Since then, there have been several additional reports documenting the development of the disease in different intertriginous areas outside the axilae, including the groin, perianal area, inframammary and abdominal folds [2-4]. Therefore, a renaming of this entitiy to "intertriginous granular parakeratosis" or simply "Granular parakeratosis" has been suggested by some authors $[2,3]$.

In a recent study by Scheinfeld et al where the incidence of GP was assessed in 363,343 biopsy specimens, only 18 cases $(0.005 \%)$ were identified and confirmed as GP and 15 of these cases were adult women and no occurrence in children was found; indicating that this is a rare condition and that adult women are more frequently affected. This study also suggested that there is a lack of awareness of this disease by dermatologist since only in one biopsy requisition form, GP was listed in the differential diagnosis [5].

Before 2002 this disease had only been reported in adults. However, recent publications have demonstrated that this condition can also occur in young children, affecting predominantly the diaper area. Two clinical patterns in the diaper region of infantile GP were described by Chang et al [6]: bilateral linear inguinal plaques and erythematous geometric plaques underlying pressure points from the diaper. Although the lesions in our patient were not located in the groin, they are more consistent with the linear plaques pattern previously described.

The cause of this entity remains unclear. Recent ultrastructural and immunohistochemical studies suggest that the pathophysiologic defect underlying this disorder is a failure in the normal degradation of profilaggrin, resulting in the retention of the keratohyaline granules within the keratinocytes [2]. The histopathologic hallmark of the disease is a markedly parakeratotic stratum corneum that has a granular appearance due to retention of keratohyalin granules.

Early reports had proposed that this disease could represent and allergic contact reaction to deodorants or antiperspirants [1-7]. However, there are several observations that argue against this hypothesis, suggesting that additional factors may be involved. These include case reports of unilateral involvement, nonaxillary intertriginous areas affected, failure to improve despite stopping or changing the suspected irritant, and the fact that in some cases no irritant could be identified [8]. Moreover, in the series of cases studied by Scheinfield and Mones, no histopathological evidence supporting an allergic contact or irritant reaction was found [5].

Physical factors such as heat, moisture and friction has also been implicated [3]. In children, occlusion from diaper, the use of baby powder and topical zinc oxide preparations have been speculated as triggering factors, but the mechanisms are unclear $[6,9]$. In our case, no lesions were observed in the diaper area and no topical products were applied to affected sites prior to the development of the rash.

In adults, the experience in the management of granular parakeratosis is limited. Various treatments have been attempted with variable efficacy. Potent topical corticosteroids have been used with success in a series of three patients [10]; while no response was observed by others [2]. Topical and systemic retinoids have been found to be effective in some patients $[8,11,12]$. There are reports of clearing with the use of topical vitamin D analogs $[4,13,14]$ and Cryotherapy was used in one patient with good results and no recurrence [1]. Some cases resolved after changing or discontinuing deodorant [2,15] and spontaneous resolution was observed in one patient [3].

Several treatment modalities have also been used in infants with granular parakeratosis, but the optimal therapy is yet to be determined. Tacrolimus, pimecrolimus, topical steroids and emollients have all been used with inconsistent results [6,9]. Keratolytics (3\%, 4\%, 5\% salicylic acid) were used with success in 4 infants reported by Giraldi et al [16]. Similarly to adults, spontaneous clearance of the lesions, as well as, complete resolution of the eruption after discontinuing topical zinc oxide preparations was noted in some patients. Our case responded to treatment with tretinoin $0,025 \%$ after 5 days of treatment.

\section{REFERENCES}

1. Northcutt AD, Nelson DM, Tschen JA: Axillary granular parakeratosis. J Am Acad Dermatol. 1991;24:541-4.

2. Metze D, Rutten A: Granular parakeratosis - a unique acquired disorder of keratinization. J Cutan Pathol. 1999;26:339-52.

3. Mehregan DA, Thomas JE, Mehregan DR: Intertriginous granular parakeratosis. J Am Acad Dermatol. 1998;39:495-6.

4. Wohlrab J, Luftl M, Wolter M, Marsch WC: Submammary granular parakeratosis: An acquired punctate hyperkeratosis of exogenic origin. J Am Acad Dermatol. 1999;40:813-4.

5. Scheinfeld NS, Mones J: Granular parakeratosis: Pathologic and clinical correlation of 18 cases of granular parakeratosis. J Am Acad Dermatol. 2005;52:863-7.

6. Chang MW, Kaufmann JM, Orlow SJ, Cohen DE, Mobini N, Kamino H: Infantile granular parakeratosis: Recognition of two clinical patterns. J Am Acad Dermatol. 2004;50:93-6.

7. Mehregan DA, Vandersteen P, Sikorski L, Mehregan DR: Axillary granular parakeratosis. J Am Acad Dermatol. 1995;33:373-5.

8. Webster CG, Resnik KS, Webster GF: Axillary granular parakeratosis: Response to isotretinoin. J Am Acad Dermatol. 1997;37:789-90.

9. Patrizi A, Neri I, Misciali C, Fanti PA: Granular parakeratosis: Four paediatric cases. Br J Dermatol. 2002;147:1003-6.

10. Chamberlain AJ, Tam MM: Intertriginous granular parakeratosis responsive to potent topical corticosteroids. Clin Experiment Dermatol. 2003;28:50-2.

11. Brown SK, Heilman ER: Granular parakeratosis: Resolution with topical tretinoin. J Am Acad Dermatol. 2002;47:279-80.

12. Comptom AK, Jackson JM: Isotetrinoin as a treatment for axillary granular parakeratosis. Cutis. 2007;80:55-6.

13. Contreras ME, Gottfried LC, Bang RH, Palmer CH: Axillary intertriginous granular parakeratosis responsive to topical calcipotriene and ammonium lactate. Int J Dermatol. 2003;42:382-3. 14. Patel U, Patel T, Skinner R: Resolution of Granular Parakeratosis with topical calcitriol. Arch Dermatol. 2011;8:997-8.

15. Barnes CJ, Lesher JL Jr, Sangueza OP: Axillary granular parakeratosis. Int J Dermatol. 2001;40:439-41.

16. Giraldi A, Simone M, Fillus Neto J, Taniguchi Abagge K, Parolin Marinonni L, Oliveira de Carvalho V, et al: Granular parakeratosis: A report of six cases in children. An Bras Dermatol. 2006;81:59-64. 17. Trowers AB, Assaf R, Jaworsky C: Granular parakeratosis in a child. Pediatr Dermatol. 2002;19:146-7.

18. Neri I, Patrizi A, Guerrini V, Fanti PA: Granular parakeratosis in a child. Dermatology. 2003;206:177-8.

19. Pimentel DR, Michalany N, Morgado de Abreu MA, Petlik B, Mota de Avelar Alchorne M: Granular parakeratosis in children: Case report and review of the literature. [see comment]. Pediatr Dermatol. 2003;20:215-20.

20. Galvis W, Jaramillo - Ayerbe F, Soto C: Paraqueratosis granulosa en niños. Rev Asoc Colomb Dermatol. 2012;20:192-5.

Copyright by Veronica Uraga, et al. This is an open access article distributed under the terms of the Creative Commons Attribution License, which permits unrestricted use, distribution, and reproduction in any medium, provided the original author and source are credited. 